Bond University

Research Repository

\title{
Antibiotics for preventing recurrent sore throat
}

Ng, Gareth J Y; Tan, Stephanie; Vu, Anh N.; Del Mar, Chris B.; van Driel, Mieke L.

Published in:

Cochrane Database of Systematic Reviews

DOI:

10.1002/14651858.CD008911.pub2

Licence:

Other

Link to output in Bond University research repository.

Recommended citation (APA):

Ng, G. J. Y., Tan, S., Vu, A. N., Del Mar, C. B., \& van Driel, M. L. (2015). Antibiotics for preventing recurrent sore throat. Cochrane Database of Systematic Reviews, 2015(7), [CD008911].

https://doi.org/10.1002/14651858.CD008911.pub2

\section{General rights}

Copyright and moral rights for the publications made accessible in the public portal are retained by the authors and/or other copyright owners and it is a condition of accessing publications that users recognise and abide by the legal requirements associated with these rights.

For more information, or if you believe that this document breaches copyright, please contact the Bond University research repository coordinator. 


\section{Cochrane Library}

Cochrane Database of Systematic Reviews

\section{Antibiotics for preventing recurrent sore throat (Review)}

Ng GJY, Tan S, Vu AN, Del Mar CB, van Driel ML

Ng GJY, Tan S, Vu AN, Del Mar CB, van Driel ML.

Antibiotics for preventing recurrent sore throat.

Cochrane Database of Systematic Reviews 2015, Issue 7. Art. No.: CD008911.

DOI: 10.1002/14651858.CD008911.pub2.

www.cochranelibrary.com 
TABLE OF CONTENTS

HEADER . . . . . . . . . . . . . . . . . . . . . . . . . . . . . . . . . . . . 1

ABSTRACT . . . . . . . . . . . . . . . . . . . . . . . . . . . . . . . . . . . . . . . . . . . . . . .

PLAIN LANGUAGE SUMMARY . . . . . . . . . . . . . . . . . . . . . . . . . . . . . . . . . . . 2

BACKGROUND . . . . . . . . . . . . . . . . . . . . . . . . . . . . . . . . . . . . . . . . .

OBJECTIVES . . . . . . . . . . . . . . . . . . . . . . . . . . . . . . . . . . . . . .

METHODS . . . . . . . . . . . . . . . . . . . . . . . . . . . . . . . . . . . . . .

Figure 1. . . . . . . . . . . . . . . . . . . . . . . . . . . . . . . . . . . . . . 5

RESULTS . . . . . . . . . . . . . . . . . . . . . . . . . . . . . . . . . . . . . . . 8

DISCUSSION . . . . . . . . . . . . . . . . . . . . . . . . . . . . . . . . . . . . .

AUTHORS' CONCLUSIONS . . . . . . . . . . . . . . . . . . . . . . . . . . . . . . . . . . 9

ACKNOWLEDGEMENTS . . . . . . . . . . . . . . . . . . . . . . . . . . . . . . . . . . . . .

REFERENCES . . . . . . . . . . . . . . . . . . . . . . . . . . . . . . . . . . . . . . 10

CHARACTERISTICS OF STUDIES . . . . . . . . . . . . . . . . . . . . . . . . . . . . . . . . . . . . . .

DATA AND ANALYSES . . . . . . . . . . . . . . . . . . . . . . . . . . . . . . . . . . . . . . . . . . . . . .

APPENDICES . . . . . . . . . . . . . . . . . . . . . . . . . . . . . . . . . . . . . 13

CONTRIBUTIONS OF AUTHORS . . . . . . . . . . . . . . . . . . . . . . . . . . . . . . . . . . . . . . . . . 17

DECLARATIONS OF INTEREST . . . . . . . . . . . . . . . . . . . . . . . . . . . . . . . . . . . . . . . . . . .

SOURCES OF SUPPORT . . . . . . . . . . . . . . . . . . . . . . . . . . . . . . . . . . . . . . . . . . . . . . . . .

DIFFERENCES BETWEEN PROTOCOL AND REVIEW . . . . . . . . . . . . . . . . . . . . . . . . . . 17

INDEX TERMS . . . . . . . . . . . . . . . . . . . . . . . . . . . . . . . . . . . . . . . . 18 


\title{
[Intervention Review]
}

\section{Antibiotics for preventing recurrent sore throat}

\author{
Gareth JY Ng${ }^{1}$, Stephanie $\operatorname{Tan}^{2}$, Anh N Vu ${ }^{2}$, Chris B Del Mar ${ }^{3}$, Mieke L van Driel ${ }^{4}$ \\ ${ }^{1}$ Royal Brisbane \& Women's Hospital, Herston, Brisbane, Australia. ${ }^{2}$ Faculty of Health Sciences and Medicine, Bond University, Gold \\ Coast, Australia. ${ }^{3}$ Centre for Research in Evidence-Based Practice (CREBP), Bond University, Gold Coast, Australia. ${ }^{4}$ Discipline of \\ General Practice, School of Medicine, The University of Queensland, Brisbane, Australia
}

Contact address: Gareth JY Ng, Royal Brisbane \& Women's Hospital, Butterfield drive, Herston, Brisbane, Queensland, Qld 4006, Australia. gareth.ng@gmail.com. gareth.ng@gmail.com.

Editorial group: Cochrane ENT Group.

Publication status and date: New, published in Issue 7, 2015.

Review content assessed as up-to-date: 25 June 2015.

Citation: Ng GJY, Tan S, Vu AN, Del Mar CB, van Driel ML. Antibiotics for preventing recurrent sore throat. Cochrane Database of Systematic Reviews 2015, Issue 7. Art. No.: CD008911. DOI: 10.1002/14651858.CD008911.pub2.

Copyright (C) 2015 The Cochrane Collaboration. Published by John Wiley \& Sons, Ltd.

\begin{abstract}
A B S T R A C T

\section{Background}

Antibiotics are sometimes used to prevent recurrent sore throat, despite concern about resistance. However, there is conflicting primary evidence regarding their effectiveness.
\end{abstract}

\section{Objectives}

To assess the effects of antibiotics in patients with recurrent sore throat.

\section{Search methods}

The Cochrane Ear, Nose and Throat Disorders Group (CENTDG) Trials Search Co-ordinator searched the CENTDG Trials Register; Central Register of Controlled Trials (CENTRAL 2015, Issue 5); PubMed; EMBASE; CINAHL; Web of Science; Clinicaltrials.gov; ICTRP and additional sources for published and unpublished trials. The date of the search was 25 June 2015.

\section{Selection criteria}

Randomised controlled trials (RCTs) of antibiotics in adults and children suffering from pre-existing recurrent sore throat, defined as three or more sore throats in a year, examining the incidence of sore throat recurrence, with follow-up of at least 12 months postantibiotic therapy.

\section{Data collection and analysis}

Two authors independently assessed trial quality and extracted data. Multiple attempts to contact the authors of one study yielded no response.

\section{Main results}

We identified no trials that met the inclusion criteria for the review. We discarded the majority of the references retrieved from our search following screening of the title and abstract. We formally excluded four studies following review of the full-text report. 


\section{Authors' conclusions}

There is insufficient evidence to determine the effectiveness of antibiotics for preventing recurrent sore throat. This finding must be balanced against the known adverse effects and cost of antibiotic therapy, when considering antibiotics for this purpose. There is a need for high quality RCTs that compare the effects of antibiotics versus placebo in adults and children with pre-existing recurrent sore throat on the following outcomes: incidence of sore throat recurrence, adverse effects, days off work and absence from school, and the incidence of complications. Future studies should be conducted and reported according to the CONSORT statement.

\section{PLAIN LANGUAGE SUMMARY}

\section{Antibiotics for preventing recurrent sore throat}

\section{Background}

Recurrent sore throat is an inflammation of the throat occurring three or more times per year. Sore throat has many causes, including bacteria, viruses, fungi (uncommonly) and non-infective causes. It causes throat pain, redness, swelling, swollen lymph nodes and symptoms of other accompanying respiratory infections. Antibiotics are sometimes used to prevent recurrent sore throat on the basis that sore throats can be caused by bacteria. However, frequent use of antibiotics has been linked to the development of antibiotic resistance. We looked for studies (randomised controlled trials) that investigated the effectiveness of antibiotics for preventing recurrent sore throat in adults and children.

\section{Study characteristics}

Despite a comprehensive search in June 2015, we were unable to identify any studies that met the inclusion criteria for this review.

\section{Key results}

No trials could be included in this review. We therefore conclude that there is insufficient evidence to determine the effectiveness of antibiotics for preventing recurrent sore throat and this finding must be balanced against the known adverse effects and cost of antibiotic therapy when considering antibiotics for this purpose. We have identified a need for high quality randomised controlled trials that compare the effects of antibiotics versus placebo in adults and children with pre-existing recurrent sore throat on the following outcomes: incidence of sore throat recurrence, adverse effects, days off work and absence from school, and the incidence of complications.

\section{B A C K G R O U N D}

\section{Description of the condition}

Throat infections (known as 'sore throat', 'pharyngitis' or 'tonsillitis', if principally affecting the tonsils) affect the respiratory mucosa of the throat. The vast majority are self limiting, that is they remit spontaneously. Throat infections cause inflammation of the mucosa and very rarely invasive infection of the potential spaces within and surrounding the oropharynx. They cause the clinical syndrome of throat pain, redness, swelling and enlarged lymph nodes, together with other symptoms of acute respiratory infection. Causes include bacteria, viruses or, uncommonly, fungi. Other causes of sore throat (sometimes accompanying systemic disease) include trauma, tumours, gastro-oesophageal reflux dis- ease and PFAPA (periodic fever, aphthous stomatitis, pharyngitis and adenitis) syndrome. Determining the aetiological agent clinically is sometimes difficult. Acute sore throats are more common in children aged three to 13 years (30\% to $40 \%$ ) than in children aged less than three years ( $5 \%$ to $10 \%)$ or adults (5\% to $15 \%)$ (eTG 2014).

Recurrent pharyngitis and tonsillitis has been defined in different ways in different studies (Blakley 2009). A definition was developed by Paradise, who studied the effect of tonsillectomy in children with severe recurrent tonsillitis: seven episodes in one year, five episodes per year for two years, or three or more episodes per year for three years (the 'Paradise criteria'). These arbitrary cutoff points were once used to guide tonsillectomy decision-making. In 2000, the criteria were relaxed by the American Academy of Otolaryngology \& Head and Neck Surgery (AAO-HNS) in their 
2000 guideline to "three or more attacks of sore throat per year despite adequate medical therapy" (AAO-HNS 2000). However, with the publication of the Academy's new, evidence-based guideline in 2011, this position has now reverted to the original and more stringent 'Paradise criteria' (AAO-HNS 2011).

Repeated episodes of acute pharyngitis/tonsillitis can cause a significant burden on families (absence from school or work) or society (healthcare costs) (Roos 1995). In a US-based survey, a relatively small proportion of children between four and 15 years old (1\%) experienced repeated group-A beta-haemolytic streptococci (GABHS) episodes in a three-year period, with the highest incidence between four and six years old (St Sauver 2006). However, at the population level this represents a significant number.

The long-term sequelae of sore throat and its infective causes include suppurative complications (quinsy, acute otitis media, acute sinusitis) and non-suppurative complications (e.g. acute rheumatic fever, acute glomerulonephritis) (eTG 2014; Ilyas 2008; Spinks 2013). Currently there are no good data on the natural history of recurrent sore throat (eTG 2014). However, an observational study on the symptoms and complications of sore throat is currently being performed in the UK (DESCARTE).

In our review, we have defined recurrent sore throat as three or more self reported episodes of sore throat per year, to include any studies undertaken during the transiently relaxed definition period.

Acute sore throat treatment include antibiotics (as well as supportive treatment including non-steroidal anti-inflammatory drugs (NSAIDs), analgesics (e.g. paracetamol) and corticosteroids).

\section{Description of the intervention}

The use of antibiotics for acute sore throat is controversial. In some countries (e.g. parts of the USA), it is routine to culture the throat to establish whether Streptococcus is the infecting agent. Whether or not to initiate antibiotic treatment is based on the result of the culture (Bisno 2002). In other countries, it is routine to use (imperfect) decision algorithms to estimate the likelihood of the cause of the symptoms being bacterial (Matthys 2007). There are large differences in clinical practice between countries (Froom 1990) and between primary care clinicians (Howie 1971). The adverse effects of antibiotic therapy include nausea, diarrhoea, major and minor allergic reactions, and development of antibiotic resistance.

\section{How the intervention might work}

Antibiotics are commonly used against any bacteria that may be causing the infection in the throat.

The rationale for using antibiotics is to remove the source of infection. Several types of antibiotics may be used, although one approach is to target group A beta haemolytic Streptococcus specifically with penicillin.

Using acute sore throat treatment as a corollary, a Cochrane review assessed the effects of antibiotics and found that they showed a slight benefit in achieving symptom reduction (Spinks 2013). Most patients (90\%) are symptom-free by seven days, regardless of whether antibiotic therapy is used or not. Antibiotics provide benefit in reducing the incidence of suppurative (e.g. quinsy) and non-suppurative complications (e.g. acute rheumatic fever and acute glomerulonephritis, attributed to infection with GABHS), but the numbers needed to treat to prevent one case are high (Spinks 2013).

It is not clear if more benefit can be expected from treatment with antibiotics in patients with frequent, recurring episodes of acute sore throat.

\section{Why it is important to do this review}

This review was prompted by the participation of one of the authors (CDM) in writing guidelines (eTG 2014). Long-term antibiotics are sometimes recommended for preventing recurrent sore throat. However, there is conflicting primary evidence regarding their effectiveness (eTG 2014). Frequent use of antibiotics adds to the burden of antibiotic resistance in the community.

The effect of antibiotics on pre-existing recurrent sore throats is not directly addressed in the Cochrane review of tonsillectomy or adenotonsillectomy versus non-surgical treatment for chronic/ recurrent acute tonsillitis (Burton 2014). The question in that review differs from this in 1) focusing on tonsillitis and 2) defining 'recurrent' as two or more episodes in a 12-month period.

\section{O B J E C T I VES}

To assess the effects of antibiotics in patients with recurrent sore throat.

\section{METHODS}

\section{Criteria for considering studies for this review}

\section{Types of studies}

Randomised controlled trials (RCTs).

We included studies that followed up patients for a minimum of 12 months post-antibiotic therapy. 


\section{Types of participants}

Adults and children who presented in any clinical setting suffering from pre-existing recurrent sore throat according to a clinical definition (where recurrent is three or more episodes per year).

\section{Types of interventions}

\section{Intervention}

All antibiotics by any route of administration, at any dose and for any duration.

We excluded combinations of antibiotics.

\section{Comparison}

Placebo.

\section{Types of outcome measures}

Primary outcomes
- Incidence of sore throat recurrence, measured by the number of self reported episodes per year (patients were followed up for a minimum of 12 months post-antibiotic therapy; we then planned to calculate the results as occurrence per year); and cumulative severity, measured in days of disability for incident cases.

- Adverse effects (including diarrhoea, thrush, rashes, nausea etc.).

\section{Secondary outcomes}

- Days off work, absence from school.

- Incidence of complications (quinsy, acute rheumatic fever, acute glomerulonephritis, acute otitis media etc.).

\section{Search methods for identification of studies}

The Cochrane Ear, Nose and Throat Disorders Group (CENTDG) Trials Search Co-ordinator (TSC) conducted systematic searches for randomised controlled trials and controlled clinical trials. There were no language, publication year or publication status restrictions. The date of the search was 25 June 2015 (Figure $1)$ 
Figure I. Process for sifting search results and selecting studies for inclusion

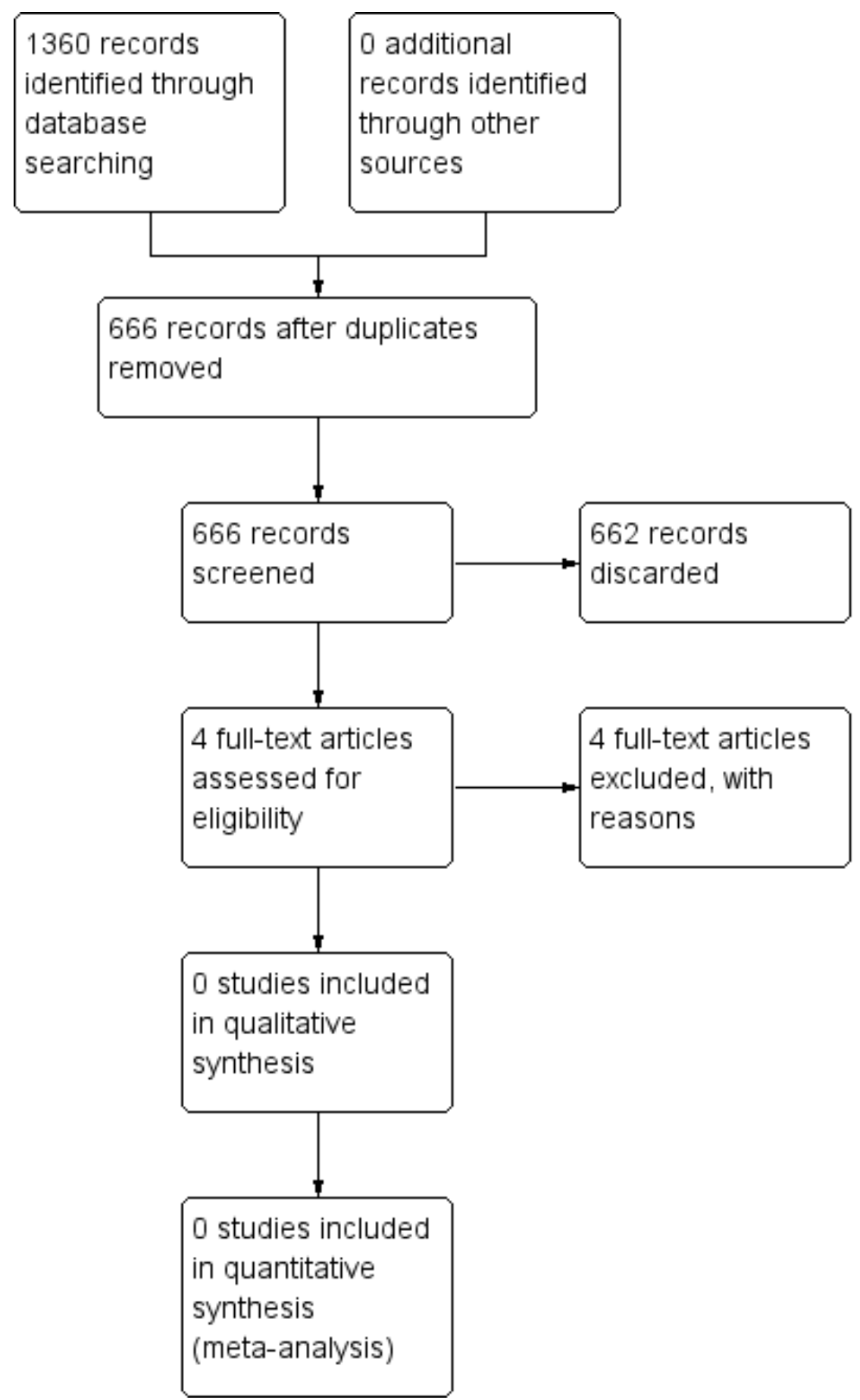




\section{Electronic searches}

The TSC searched:

- the CENTDG Trials Register (searched 25 June 2015);

- the Cochrane Central Register of Controlled Trials

(CENTRAL 2015, Issue 5);

- PubMed (1946 to 25 June 2015);

- Ovid EMBASE (1974 to 2015 week 25);

- Ovid CAB Abstracts (1910 to 2015 week 24);

- EBSCO CINAHL (1982 to 25 June 2015);

- LILACS, lilacs.bvsalud.org (searched 25 June 2015);

- KoreaMed (searched via Google Scholar 25 June 2015);

- IndMed, www.indmed.nic.in (searched 25 June 2015);

- PakMediNet, www.pakmedinet.com (searched 25 June 2015);

- Web of Knowledge, Web of Science (1945 to 25 June 2015);

- CNKI, www.cnki.com.cn (searched via Google Scholar 25 June 2015);

- ClinicalTrials.gov (searched via the Cochrane Register of Studies 25 June 2015);

- ICTRP, www.who.int/ictrp (searched 25 June 2015);

- ISRCTN www.isrctn.com (searched 25 June 2015);

- Google Scholar, scholar.google.co.uk (searched 25 June 2015);

- Google, www.google.com (searched 25 June 2015).

In searches prior to 2013, we also searched BIOSIS Previews 1926 to 2012 .

The TSC modelled subject strategies for databases on the search strategy designed for CENTRAL. Where appropriate, they were combined with subject strategy adaptations of the highly sensitive search strategy designed by The Cochrane Collaboration for identifying randomised controlled trials and controlled clinical trials (as described in the Cochrane Handbook for Systematic Reviews of Interventions Version 5.1.0, Box 6.4.b. (Handbook 2011). Search strategies for major databases including CENTRAL are provided in Appendix 1.

\section{Searching other resources}

We scanned the reference lists of identified publications for additional trials and contacted trial authors where necessary. In addition, the TSC searched PubMed, TRIPdatabase, The Cochrane Library and Google to retrieve existing systematic reviews relevant to this systematic review, so that we could scan their reference lists for additional trials.

\section{Data collection and analysis}

\section{Selection of studies}

Initially we analysed the titles and abstracts from the searches. We then acquired the full text of the studies that potentially met the eligibility criteria. We then also obtained full-text articles if eligibility of the study could not be determined due to insufficient information supplied in the abstract or absence of an abstract. Two authors (AV and ST) independently assessed study eligibility to ensure they met the inclusion criteria for the review. We resolved any disagreements over which studies to include by discussion and consensus, or if disagreement could not be resolved by these methods, we consulted a third author (CDM). Where clarification was required, we contacted the study authors to request the relevant information. We documented the reasons for exclusion of studies.

\section{Data extraction and management}

Two authors (GN and ST) independently extracted data using standardised, pre-piloted data collection forms. Collection forms included:

1. authors;

2. publication year;

3. name of journal;

4. participants (including total number, demographics, duration and characteristics of illness etc.);

5. intervention (type of antibiotic, route and duration); and

6. results (outcome measures, time points, effect, statistical significance, adverse effects).

We resolved any disagreements by discussion and consensus or if disagreement could not be resolved by these methods, we consulted a third author (CDM). Where clarification was required, we contacted the study authors to request the relevant information. If disagreement remained unresolved, we reported disagreement in the review.

We tabulated extracted information in a spreadsheet using Microsoft Excel before entering data into RevMan 5 (RevMan 2014). We made all statistical conversions using a computer to ensure complete recording, as advised in Chapter 7.8 'Managing data' in the Cochrane Handbook for Systematic Reviews of Interventions (Handbook 2011).

\section{Assessment of risk of bias in included studies}

Two authors (AV and GN) planned to assess independently the risk of bias of each trial using the standard Cochrane criteria ( Handbook 2011), with the following taken into consideration:

- sequence generation;

- allocation concealment;

- blinding;

- incomplete outcome data;

Antibiotics for preventing recurrent sore throat (Review) 
- selective outcome reporting; and

- other sources of bias.

We planned to use the Cochrane 'Risk of bias' tool in RevMan 5, which involves describing each of these domains as reported in the trial and then assigning a judgement about the adequacy of each entry: 'low', 'high' or 'unclear' risk of bias.

Any disagreements would have been resolved by discussion and consensus or if disagreement could not be resolved by these methods, a third author (MVD) was to be consulted. Where clarification was required, we planned to contact the study authors to request the relevant information. If disagreement remained unresolved, this was to be reported in review.

\section{Measures of treatment effect}

For numerical data, if outcomes were measured in the same way we used the mean difference (MD) (+/- standard deviation (SD)) to compare the differences between groups. We planned to combine trials that measured the same outcome but used different methods using the standardised mean difference (SMD).

For dichotomous data, we planned to present the results as odds ratios (OR) with $95 \%$ confidence intervals (CI).

\section{Unit of analysis issues}

The unit of analysis was the unit of randomisation. For repeated observations on participants, we intended to avoid unit of analysis errors by defining different outcomes based on different periods of follow-up and by performing separate analyses. For events that may have re-ocurred, we would have taken care to avoid unit of analysis issues. In the case of cluster-randomised trials we planned to make appropriate adjustment for clustering according to the guidelines outlined in the Cochrane Handbook for Systematic Reviews of Interventions (Handbook 2011).

\section{Dealing with missing data}

We planned intention-to-treat analysis when possible (assuming missing data as treatment failure).

\section{Assessment of heterogeneity}

We would have assessed heterogeneity between trials with a twostepped approach. First, we planned to assess heterogeneity at face value (e.g. when populations differ substantially or where setting and/or treatment are different). Second, we planned to assess statistical heterogeneity by performing a $\mathrm{Chi}^{2}$ test and calculating the $\mathrm{I}^{2}$ statistic. Cut-off values for the $\mathrm{I}^{2}$ statistic would have followed the guidelines in the Cochrane Handbook for Systematic Reviews of Interventions (Handbook 2011). We planned to describe identified sources of heterogeneity.

\section{Assessment of reporting biases}

We planned to investigate reporting biases (such as publication bias) by using funnel plots when there were 10 or more studies eligible for meta-analysis. If the outcomes were dichotomous, we planned to assess the funnel plot using the approach proposed by Egger (Egger 1997). For continuous outcomes, we planned to assess the funnel plot using the tests proposed by Harbord (Harbord 2006).

\section{Data synthesis}

We synthesised data using the Review Manager software (RevMan 5.3) (RevMan 2014).

In the absence of important heterogeneity we planned to use a fixed-effect model. We did not intend to pool trials found to be heterogeneous or, in the case of statistical heterogeneity, we would have pooled studies using a random-effects model (Handbook 2011).

\section{Subgroup analysis and investigation of heterogeneity}

Planned subgroup analyses included:

1. children versus adults;

2. children under two years versus older children; and

3. risk of bias (low versus high risk of bias).

\section{Sensitivity analysis}

If heterogeneity had been present, we would have examined the methodological and clinical characteristics of the included trials to explore the causes. We would then have determined the impact of any clinical or methodological differences found by performing sensitivity analyses.

We planned to produce a summary table to report all sensitivity analyses.

\section{'Summary of findings' table}

In future updates of this review, if studies are included, we will use the GRADE approach to rate the overall quality of evidence. The quality of evidence reflects the extent to which we are confident that an estimate of effect is correct and we will apply this in the interpretation of results. There are four possible ratings: high, moderate, low and very low. A rating of high quality of evidence implies that we are confident in our estimate of effect and that further research is very unlikely to change our confidence in the estimate of effect. A rating of very low quality implies that any estimate of effect obtained is very uncertain.

The GRADE approach rates evidence from RCTs that do not have serious limitations as high quality. However, several factors can lead to the downgrading of the evidence to moderate, low or very low. The degree of downgrading is determined by the seriousness of the these factors: 
- study limitations (risk of bias);

- inconsistency;

- Indirectness of evidence;

- imprecision; and

- publication bias.

We will include a 'Summary of findings' (SOF) table, constructed according to the recommendations described in Chapter 11 of the Cochrane Handbook for Systematic Reviews of Interventions ( Handbook 2011).

\section{R E S U L T S}

\section{Description of studies}

\section{Results of the search}

The search retrieved a total of 1360 references. We excluded 694 of these in first-level screening (i.e. removal of duplicates and clearly irrelevant references), leaving 666 references for further consideration. Out of those 666 studies, we discarded 455 following screening of the title and 207 on the basis of the abstract. We excluded the remaining four studies after the full text was obtained and studied. There are no studies 'awaiting assessment' or 'ongoing' studies. Figure 1 depicts a flow chart of the study screening and selection process.

\section{Included studies}

No studies met the inclusion criteria.

\section{Excluded studies}

See Characteristics of excluded studies.

We excluded four studies following review of the full text (Jensen 1991; Liltholdt 2003; Mora 2003; Sirimanna 1990). We excluded Jensen 1991 because the authors did not compare antibiotic treatment with placebo (they compared with no antibiotic treatment) and tonsillectomy was conducted before follow-up was complete. We excluded Liltholdt 2003 because tonsillectomy was carried out before follow-up was complete. We excluded Mora 2003 because the results were uninterpretable. We made numerous attempts to contact the investigators for further information, however no response was received. We excluded Sirimanna 1990 because the authors compared antibiotic treatment with no treatment instead of placebo.

\section{Risk of bias in included studies}

No studies were included.

\section{Effects of interventions}

No studies were included.

\section{DISCUSSION}

\section{Summary of main results}

Given the fact that recurrent sore throat is a relatively common clinical condition, we were surprised that there were no studies available that addressed our clinical question. Most studies have been performed in ENT outpatient settings and compared the effects of antibiotics versus tonsillectomy, or the effectiveness of different antibiotics. However, research in primary care and into the effectiveness of antibiotics versus placebo is lacking. Further research is necessary to help determine the best management of patients with recurrent sore throat.

\section{Overall completeness and applicability of evidence}

Does recommending antibiotic therapy for recurrent sore throat reduce the number of future episodes per year? Are there adverse effects from recommending antibiotics for recurrent sore throat? Does recommending antibiotics for recurrent sore throat reduce the amount of days taken off work or absent from school? Does recommending antibiotics for recurrent sore throat reduce the incidence of complications? There are currently no studies to answer any of these questions.

\section{Quality of the evidence}

We were unable to include any studies in this review.

\section{Potential biases in the review process}

Were we too strict in our inclusion criteria? Perhaps we could have also included non-randomised studies? This could be regarded as a potential source of bias. However, the inclusion of non-randomised studies would have diluted the quality of evidence from any randomised controlled trials (RCTs) and this would have introduced a risk of bias in the overall effect estimate.

Another potential source of bias was our inability to obtain information from a trial author. Mora 2003 conducted a RCT in 
children with recurrent tonsillitis, but the abstract provided insufficient information for us to decide on inclusion. The authors of the study did not respond to our requests for information despite multiple attempts.

\section{Agreements and disagreements with other studies or reviews}

No other systematic reviews have been published on this topic. The question of whether there are any adverse effects from recommending antibiotics for recurrent sore throat was addressed by three of the formally excluded studies:

Jensen 1991 suggested that there were potential adverse effects from recommending antibiotics in recurrent sore throat and reported that $24 \%$ of patients taking clindamycin stopped treatment because of adverse effects: $13 \%$ complained of diarrhoea, $11 \%$ of abdominal pain, $2 \%$ of anogenital itching and $2 \%$ of dizziness. However, the study comparison was not versus placebo (antibiotics versus tonsillectomy).

Lildholdt 2003 found that $25 \%$ of patients receiving azithromycin complained of gastrointestinal pain and $2 \%$ complained of rash, whilst $4 \%$ of those receiving placebo complained of rash and none of gastrointestinal pain.

Mora 2003 suggested that there were no side effects from antibiotic therapy when compared to placebo.

The apparent variation in the incidence of side effects of antibiotic therapy when compared to placebo may be related to the type of antibiotic and duration of treatment. However, there were no trials available that could to provide an explanation for this finding. Further research needs to determine the risk/benefit of prescribing antibiotics for recurrent sore throat.

Another potential benefit from antibiotics would be to reduce the duration and severity of illness. Interestingly, none of the excluded studies reported the amount of days taken off work or absent from school as an outcome measure for severity and duration of disease. Mora 2003 suggested a marked decrease in the severity of symptoms on a subjective evaluation scale following administration of antibiotics. The severity score of symptoms on a scale between zero and four showed that those treated with antibiotics had a mean decrease in severity from $2.61 / 4$ to $0.88 / 4$, whilst those treated with placebo had only a $2.53 / 4$ to $2.20 / 4$ decrease. A more objective measure, such as time taken off work or absence from school, would be more clinically relevant.

Further research needs to determine whether antibiotics cause a reduction in the duration and severity of recurrent sore throat.

An important complication of recurrent sore throat is the development of a peritonsillar abscess. Sirimana 1990 reported that of the untreated people with recurrent sore throat, $4 \%$ developed peritonsillar abscesses and $28 \%$ deteriorated to the extent of requiring treatment in the form of tonsillectomy or antibiotic treatment due to recurrent tonsillitis. However, they compared antibiotics to no treatment (rather than placebo) and did not report the number of complications in those treated with antibiotics.

Further research also needs to determine whether antibiotics reduce the incidence of complications in those with recurrent sore throat.

The formally excluded studies did not answer our clinical question and those that seemed to address it did not report any of the outcome measures that we defined for this review a priori. Two of these studies presented results that could be misinterpreted. In addition, two of the studies made no attempt at blinding. At least three of the four studies included participants referred to ENT specialists, so extrapolation to patients in the primary care setting is problematic. This is of significance, as most patients with recurrent sore throat will not be referred to ENT specialists and it is likely that most of those that are referred to ENT would be more severe. There is insufficient evidence to support guidelines, e.g. eTG 2014 , or recommendations about long-term antibiotic therapy to prevent recurrent sore throat. However, the lack of evidence to determine the effectiveness of antibiotics for preventing recurrent sore throat must be balanced against the known adverse effects and cost of antibiotic therapy, when considering antibiotics for this purpose.

\section{A U THORS' CONCLUSIONS}

\section{Implications for practice}

Currently there is insufficient evidence from randomised trials to guide clinicians on the effectiveness of antibiotics to prevent recurrent sore throat. However, this finding must be balanced against the known adverse effects and cost of antibiotic therapy, when considering antibiotics for this purpose.

\section{Implications for research}

High quality randomised controlled trials (RCTs) are needed to determine any benefit or harm from antibiotics for preventing recurrent sore throat.

We recommend that RCTs in the future should include adults and children who are suffering from pre-existing recurrent sore throat, where recurrent is defined as three or more episodes of sore throat per year. These trials should investigate the effect of antibiotics by any route of administration and for any duration (excluding combination antibiotics) versus a placebo comparison. The most clinically important outcomes measured should include the incidence of sore throat recurrence, adverse effects, days off work, absence from school and the incidence of complications, with patients followed up for a minimum of 12 months.

RCTs addressing this issue should follow the CONSORT Statement to enable transparency and ensure the validity of the results presented. 


\section{ACKNOWLEDGEMENTS}

Assistance was given by the Cochrane Ear, Nose \& Throat Disorders Group including Samantha Faulkner (Trial Search Co-ordinator and Assistant Managing Editor), who performed the searches and helped us gain access to full-text articles.

This project was supported by the National Institute for Health Research, via Cochrane Infrastructure, Cochrane Programme Grant or Cochrane Incentive funding to the Cochrane ENT Group. The views and opinions expressed therein are those of the authors and do not necessarily reflect those of the Systematic Reviews Programme, NIHR, NHS or the Department of Health.

\section{RE F E R E N C E S}

\section{References to studies excluded from this review}

Jensen 1991 \{published data only\}

Jensen J, Larsen S. Treatment of recurrent tonsillitis with clindamycin. An alternative to tonsillectomy?. Clinical Otolaryngology and Allied Sciences 1991;16:498-500.

Liltholdt 2003 \{published data only\}

Lildholdt T, Doessing H, Lyster M, Oetzen KE. The natural history of recurrent acute tonsillitis and a clinical trial of azithromycin for antibiotic prophylaxis. Clinical Otolaryngology and Allied Sciences 2003;28(4):371-3.

Mora 2003 \{published and unpublished data\}

Mora R, Salami A, Francesco M, Cordone M, Ottoboni S, Passali G, et al. Efficacy of cefpodoxime in the prophylaxis of recurrent pharyngotonsillitis. International Journal of Pediatric Otorhinolaryngology 2003;67 Suppl 1:S225-8.

Sirimanna 1990 \{published data only (unpublished sought but not used)\}

Sirimana KS, Madden GJ, Miles SM. The use of longacting penicillin in the prophylaxis of recurrent tonsillitis. Journal of Otolaryngology 1990;100:343-4.

\section{Additional references}

\section{AAO-HNS 2000}

AAO-HNS. Clinical indicators: tonsillectomy, adenoidectomy, adenotonsillectomy. Clinical Indicators Compendium () 2000 (accessed 1 November 2010).

\section{AAO-HNS 2011}

Baugh RF, Archer SM, Mitchell RB, Rosenfeld RM, Amin $\mathrm{R}$, Burns JJ, et al. Clinical practice guideline: tonsillectomy in children. Otolaryngology - Head and Neck Surgery 2011; 144:S1-30. [DOI: 10.1177/0194599810389949]

\section{Bisno 2002}

Bisno AL, Gerber MA, Gwaltney JM, Kaplan EL, Schwartz RH. Practice guidelines for the diagnosis and management of group A streptococcal pharyngitis. Clinical Infectious Diseases 2002;35(2):113-25.

\section{Blakley 2009}

Blakley BW, Magit AE. The role of tonsillectomy in reducing recurrent pharyngitis: a systematic review. Otolaryngology - Head and Neck Surgery 2009;140:291-7.

\section{Burton 2014}

Burton MJ, Glasziou PP, Chong LY, Venekamp RP. Tonsillectomy or adenotonsillectomy versus non-surgical treatment for chronic/recurrent acute tonsillitis. Cochrane Database of Systematic Reviews 2014, Issue 11. [DOI: 10.1002/14651858.CD001802.pub3]

\section{CONSORT Statement}

Schulz KF, Altman DG, Moher D, for the CONSORT Group. CONSORT Statement 2010. http://www.consortstatement.org.

\section{DESCARTE}

Little P. DEcision rule for severe Symptoms and Complications of Acute Red Throat in Everyday practice (DESCARTE). http://public.ukcrn.org.uk/search/ StudyDetail.aspx?StudyID=2421 (accessed 18 April 2014).

Egger 1997

Egger M, Smith GD, Schneider M, Minder C. Bias in meta-analysis detected by a simple, graphical test. $B M J$ 1997;315:629-34.

eTG 2014

Pharyngitis and/or tonsillitis. eTG complete http:// www.etg.hcn.net.au/ Revised October 2014 (accessed 22 February 2015).

\section{Froom 1990}

Froom J, Culpepper L, Grob P, Bartelds A, Bowers P, Bridges-Webb C, et al. Diagnosis and antibiotic treatment of acute otitis media: report from International Primary Care Network. BMJ 1990;300:582-6.

\section{Handbook 2011}

Higgins JPT, Green S (editors). Cochrane Handbook for Systematic Reviews of Interventions Version 5.1.0 [updated March 2011]. The Cochrane Collaboration, 2011. Available from www.cochrane-handbook.org. 


\section{Harbord 2006}

Harbord RM, Egger M, Sterne JA. A modified test for small-study effects in meta-analyses of controlled trials with binary endpoints. Statistics in Medicine 2006;25:3443-57.

\section{Howie 1971}

Howie JGR, Gill G, Durno D. Respiratory illness and antibiotic use in general practice. Journal of the Royal College of General Practitioners 1971;21:657-61.

\section{Ilyas 2008}

Ilyas M, Tolaymat A. Changing epidemiology of acute poststreptococcal glomerulonephritis in Northeast Florida: a comparative study. Pediatric Nephrology 2008;23(7): 1101-67.

\section{Lildholdt 2003}

Lildholdt, Doessing H, Lyster M, Outzen KE. The natural history of recurrent acute tonsillitis and a clinical trial of azithromycin for antibiotic prophylaxis. Clinical Otolaryngology 2003;28:371-3.

\section{Matthys 2007}

Matthys J, De Meyere M, van Driel ML, De Sutter A. Differences among international pharyngitis guidelines: not just academic. Annals of Family Medicine 2007;5:436-43.

\section{RevMan 2014 [Computer program]}

The Nordic Cochrane Centre, The Cochrane Collaboration. Review Manager (RevMan). Version 5.3. Copenhagen: The Nordic Cochrane Centre, The Cochrane Collaboration, 2014.

\section{Roos 1995}

Roos K, Claesson R, Persson U, Odegaard K. The economic cost of a streptococcal tonsillitis episode. Scandinavian Journal of Primary Health Care 1995;13:257-60.

\section{Sirimana 1990}

Sirimanna KS, Madden GJ, Miles SM. The use of longacting penicillin in the prophylaxis of recurrent tonsillitis. Journal of Otolaryngology 1990;100:343-4.

\section{Spinks 2013}

Spinks A, Glasziou PP, Del Mar CB. Antibiotics for sore throat. Cochrane Database of Systematic Reviews 2013, Issue 11. [DOI: $10.1002 / 14651858 . C D 000023 . p u b 4]$

\section{St Sauver 2006}

St Sauver JL, Weaver AL, Orvidas LJ, Jacobson RM, Jacobsen SJ. Population-based prevalence of repeated group A $\beta$-hemolytic streptococcal pharyngitis episodes. Mayo Clinic Proceedings 2006;81(9):1172-6.

* Indicates the major publication for the study 


\section{CHARACTERISTICS OF STUDIES}

\section{Characteristics of excluded studies [ordered by study ID]}

\begin{tabular}{|c|c|}
\hline Study & Reason for exclusion \\
\hline Jensen 1991 & $\begin{array}{l}\text { ALLOCATION: } \\
\text { Randomised controlled trial, non-blinded } \\
\text { PARTICIPANTS: } \\
54 \text { patients with recurrent acute tonsillitis ( }>3 \text { episodes in the previous } 2 \text { years) } \\
\text { INTERVENTIONS: } \\
150 \text { mg clindamycin } 4 \text { times a day for } 10 \text { days versus no antibiotic treatment (no placebo used). } 28 \text { of the included } \\
\text { patients in both arms had a tonsillectomy within the } 1 \text {-year period } \\
\text { Excluded because no placebo used and tonsillectomy was used for treatment before follow-up was complete }\end{array}$ \\
\hline Liltholdt 2003 & $\begin{array}{l}\text { ALLOCATION: } \\
\text { Randomised controlled trial, blinded } \\
\text { PARTICIPANTS: } \\
110 \text { patients (adults and children) with recurrent acute tonsillitis (> } 3 \text { episodes in the past } 2 \text { years) } \\
\text { INTERVENTIONS: } \\
\text { Azithromycin } 500 \mathrm{mg} \text { or placebo once a week for } 6 \text { months. If any patient had confirmed acute tonsillitis, it was } \\
\text { considered failed treatment and they were offered tonsillectomy } \\
\text { Excluded because tonsillectomy was used as treatment before follow-up was complete }\end{array}$ \\
\hline Mora 2003 & $\begin{array}{l}\text { ALLOCATION: } \\
\text { Randomised controlled trial } \\
\text { PARTICIPANTS: } \\
180 \text { children with recurrent pharyngotonsillitis (at least } 3 \text { episodes in the past year) } \\
\text { INTERVENTIONS: } \\
\text { Cefpodoxime proxetil ( } 100 \mathrm{mg} \text { twice a day, } 6 \text { days a month for } 6 \text { months) versus placebo } \\
\text { OUTCOMES: } \\
\text { Authors reported that cefpodoxime may be effective in reducing symptoms of recurrent pharyngotonsillitis and } \\
\text { preventing recurrences } \\
\text { Excluded because the results were uninterpretable; we made numerous attempts to contact the investigators } \\
\text { but received no response }\end{array}$ \\
\hline Sirimanna 1990 & $\begin{array}{l}\text { ALLOCATION: } \\
\text { Randomised controlled trial, non-blinded } \\
\text { PARTICIPANTS: } \\
\text { Patients with recurrent tonsillitis (> } 4 \text { attacks in the past year) } \\
\text { INTERVENTIONS: intramuscular dose of benzathine penicillin each month for } 6 \text { months versus no treatment } \\
\text { Excluded because no treatment was used as a comparison }\end{array}$ \\
\hline
\end{tabular}




\section{DATA ANDANALYSES}

This review has no analyses.

\section{A P PENDICES}

\section{Appendix I. Search strategies}

\begin{tabular}{|c|c|c|}
\hline CENTRAL & EMBASE (Ovid) & PubMed \\
\hline $\begin{array}{l}\text { \#1 MeSH descriptor Pharyngi- } \\
\text { tis explode all trees } \\
\text { \#2 pharyngit* } \\
\text { \#3 MeSH descriptor Na- } \\
\text { sopharyngitis explode all trees } \\
\text { \#4 (Retropharyngeal OR Peri- } \\
\text { tonsillar) NEAR Abscess } \\
\text { \#5 nasopharyngit* } \\
\text { \#6 MeSH descriptor Tonsillitis } \\
\text { explode all trees } \\
\text { \#7 tonsillit* } \\
\text { \#8 (SORE* or INFLAMM* or } \\
\text { INFECT*) NEAR THROAT } \\
\text { \#9 Pharyngotonsillitis } \\
\text { \#10 (\#1 OR \#2 OR \#3 OR \#4 } \\
\text { OR \#5 OR \#6 OR \#7 OR \#8 } \\
\text { OR \#9) descriptor } \\
\text { \#11 MeSH descriptor Anti- } \\
\text { Bacterial Agents explode all } \\
\text { trees } \\
\text { \#12 MeSH descriptor Antibi- } \\
\text { otic Prophylaxis explode all } \\
\text { trees } \\
\text { \#13 MeSH descriptor Lactams } \\
\text { explode all trees } \\
\text { \#14 MeSH } \\
\text { Quinolones explode all trees } \\
\text { \#15 MeSH } \\
\text { Macrolides explode all trees } \\
\text { \#16 antibiot* OR (anti ADJ } \\
\text { biot*) OR antimicrobial* OR } \\
\text { (anti ADJ microbial*) OR bac- } \\
\text { teriocid* OR antibacterial* OR } \\
\text { (anti ADJ bacterial*) } \\
\text { \#17 penicillin* OR amoxicillin } \\
\text { OR ampicillin OR clavulanic }\end{array}$ & $\begin{array}{l}1 \text { *sore throat/ } \\
2 \text { exp *pharyngitis/ } \\
3 \text { exp *tonsillitis/ } \\
4 \text { (pharyngit* or nasopharyn- } \\
\text { git* or (retropharyngeal and } \\
\text { abscess) or (peritonsillar and } \\
\text { abscess) or tonsillit* or (sore } \\
\text { and throat) or (inflamm* and } \\
\text { throat) or (infect* and throat) } \\
\text { or pharyngotonsillitis).ti. } \\
51 \text { or } 2 \text { or } 3 \text { or } 4 \\
6 \text { recurrent infection/ } \\
7 \text { chronic disease/ } \\
8 \text { exp relapse/ } \\
9 \text { (recurr* or recrudesc* or re- } \\
\text { laps* or reappear* or chronic* } \\
\text { or prophyla* or prevent*).tw. } \\
106 \text { or } 7 \text { or } 8 \text { or } 9 \\
115 \text { and } 10 \\
12 \text { chronic tonsillitis/ } \\
1311 \text { or } 12 \\
14 \text { exp antibiotic agent/ } \\
15 \text { exp lactam/ } \\
16 \text { exp quinolone derivative/ } \\
17 \text { (antibiot* or (anti and } \\
\text { biot*) or antimicrobial* or (anti } \\
\text { and microbial*) or bacterio- } \\
\text { cid or antibacterial* or (anti } \\
\text { and bacterial*) or penicillin* } \\
\text { or amoxicillin or ampicillin or } \\
\text { (clavulanic and acid) or amoxi- } \\
\text { clav or augmentin or ticarcillin } \\
\text { or timentin or flucloxacillin } \\
\text { or fluampicil or magnapen } \\
\text { or piperacillin or tazocin or } \\
\end{array}$ & $\begin{array}{l}\text { \#1 "Pharyngitis" [Mesh] OR } \\
\text { "Nasopharyngitis" [Mesh] OR } \\
\text { "Tonsillitis" [Mesh] } \\
\text { \#2 pharyngit* [ti] OR na- } \\
\text { sopharyngit* [ti] OR (retropha- } \\
\text { ryngeal [ti] AND abscess [ti]) } \\
\text { OR (peritonsillar [ti] AND ab- } \\
\text { scess [ti]) OR tonsillit* [ti] OR } \\
\text { (sore [ti] AND throat [ti]) OR } \\
\text { (inflamm* [ti] AND throat [ti]) } \\
\text { OR (infect* [ti] AND throat } \\
\text { [ti]) OR pharyngotonsillitis [ti] } \\
\text { \#3 \#1 OR \#2 } \\
\text { \#4 "Recurrence"[Mesh] OR } \\
\text { "Chronic Disease"[Mesh] } \\
\text { \#5 "Secondary Prevention" } \\
\text { [Mesh] } \\
\text { \#6 recurr* [tiab] OR recrudesc* } \\
\text { [tiab] OR relaps* [tiab] OR } \\
\text { reappear* [tiab] chronic* [tiab] } \\
\text { OR prophyla* [tiab] OR pre- } \\
\text { vent* [tiab] } \\
\text { \#7 \#4 OR \#5 OR \#6 } \\
\text { \#8 \#3 AND \#7 } \\
\text { \#9 "antibiotic prophylaxis" } \\
\text { [Mesh] } \\
\text { \#10 \#3 AND \#9 } \\
\text { \#11 "anti-bacterial agents" } \\
\text { [Mesh] OR "lactams" [Mesh] } \\
\text { OR “quinolones" [Mesh] OR } \\
\text { "macrolides" [Mesh] } \\
\text { \#12 (antibiot* [tiab] OR (anti } \\
\text { [tiab] AND biot* [tiab]) OR } \\
\text { antimicrobial* [tiab] OR (anti } \\
\text { [tiab] AND microbial* [tiab]) }\end{array}$ \\
\hline
\end{tabular}

Antibiotics for preventing recurrent sore throat (Review) 
acid OR amoxiclav OR augmentin OR ticarcillin OR timentin OR flucloxacillin OR fluampicil OR magnapen OR piperacillin OR tazocin \#18 cephalosporin* OR cefaclor OR distaclor OR cefadroxil OR baxan OR cefalexin OR ceporex OR keflex OR cefamandole OR kefadol OR cefazolin OR kefzol OR cefixime OR suprax OR cefotaxime OR claforan OR cefoxitin OR mefoxin OR cefpirome OR cefrom OR cefpodoxime OR orelox OR cefprozil OR cefzil OR cefradine OR velosel OR ceftazidime OR fortum OR kefadim OR ceftriaxone OR rocephin OR cefuroxime OR zinacef OR zinnat OR cefonicid OR aztreonam OR azactam OR imipenem OR cilastatin OR primaxin OR meropenem or meronem or tetracycline* or deteclo or demecleocyclin or ledermycin or doxycycline or vibramycin or minocycline or minocine or oxytetracycline or terramycin

\#19 macrolide*

OR erythromycin OR erymax OR erythrocin OR erythroped OR azithromycin OR zithromax OR clarithromycin OR klaricid OR telithromycin OR ketek OR trimoxazole OR septrin OR trimethoprim OR monotrim $\mathrm{OR}$ trimopan $\mathrm{OR}$ metronidazole OR flagyl OR metrolyl

\#20 quinolone* OR ciprofloxa-

cin OR ciproxin

\#21 (\#11 OR \#12 OR \#13 OR \#14 OR \#15 OR \#16 OR \#17 OR \#18 OR \#19 OR \#20)

\#22 (\#10 AND \#21)

\#23 MeSH descriptor Recurrence explode all trees cephalosporin* or cefaclor or distaclor or cefadroxil or baxan or cefalexin or ceporex or keflex or cefamandole or kefadol or cefazolin or kefzol or cefixime or suprax or cefotaxime or claforan or cefoxitin or mefoxin or cefpirome or cefrom or cefpodoxime or orelox or cefprozil or cefzil or cefradine or velosel or ceftazidime or fortum or kefadim or ceftriaxone or rocephin or cefuroxime or zinacef or zinnat or cefonicid or aztreonam or azactam or imipenem or cilastatin).ti.

18 (primaxin or meropenem or meronem or tetracycline* or deteclo or demecleocyclin or ledermycin or doxycycline or vibramycin or minocycline or minocine or oxytetracycline or terramycin or macrolide* or erythromycin or erymax or erythrocin or erythroped or azithromycin or zithromax or clarithromycin or klaricid or telithromycin or ketek or trimoxazole or septrin or trimethoprim or monotrim or trimopan or metronidazole or flagyl or metrolyl or quinolone* or ciprofloxacin or ciproxin).ti. 1914 or 15 or 16 or 17 or 18 2013 and 19

21 antibiotic prophylaxis/

225 and 21

2320 or 22
OR bacteriocid [tiab] OR antibacte-

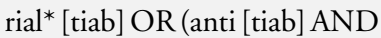
bacterial* $^{*}$ tiab]) OR penicillin* [tiab] OR amoxicillin [tiab] OR ampicillin [tiab] OR (clavulanic [tiab] AND acid [tiab]) OR amoxiclav [tiab] OR augmentin [tiab] OR ticarcillin [tiab] OR timentin [tiab] OR flucloxacillin [tiab] OR fluampicil [tiab] OR magnapen [tiab] OR piperacillin [tiab] OR tazocin [tiab] OR cephalospOR in* [tiab] OR cefaclOR [tiab] OR distaclOR [tiab] OR cefadroxil [tiab] OR baxan [tiab] OR cefalexin [tiab] OR ceporex [tiab])

\#13 (keflex [tiab] OR cefamandole [tiab] OR kefadol [tiab] OR cefazolin [tiab] OR kefzol [tiab] OR cefixime [tiab] OR suprax [tiab] OR cefotaxime [tiab] OR claforan [tiab] OR cefoxitin [tiab] OR mefoxin [tiab] OR cefpirome [tiab] OR cefrom [tiab] OR cefpodoxime [tiab] OR [tiab] OR elox [tiab] OR cefprozil [tiab] OR cefzil [tiab] OR cefradine [tiab] OR velosel [tiab] OR ceftazidime [tiab] OR f[tiab] OR tum [tiab] OR kefadim [tiab] OR ceftriaxone [tiab] OR rocephin [tiab] OR cefuroxime [tiab] OR zinacef [tiab] OR zinnat [tiab] OR cefonicid [tiab] OR aztreonam [tiab] OR azactam [tiab] OR imipenem [tiab] OR cilastatin)

\#14 (primaxin [tiab] OR meropenem [tiab] OR meronem [tiab] OR tetracycline* [tiab] OR deteclo [tiab] OR demecleocyclin [tiab] OR ledermycin [tiab] OR doxycycline [tiab] OR vibramycin 
\#24 recurr* ${ }^{*}$ or recrudesc* or re-

laps* or reappear*

\#25 MeSH descriptor Secondary Prevention explode all trees

\#26 prophyla* or prevent*

\#27 (\#23 OR \#24 OR \#25 OR

\#26)

\#28 (\#22 AND \#27) [tiab] OR minocycline [tiab] OR minocine [tiab] OR oxytetracycline [tiab] OR terramycin [tiab] OR macrolide* [tiab] OR erythromycin [tiab] OR erymax [tiab] OR erythrocin [tiab] OR erythroped [tiab] OR azithromycin [tiab] OR zithromax [tiab] OR clarithromycin [tiab] OR klaricid [tiab] OR telithromycin [tiab] OR ketek [tiab] OR trimoxazole [tiab] OR septrin [tiab] OR trimethoprim [tiab] OR monotrim [tiab] OR trimopan [tiab] OR metronidazole [tiab] OR flagyl [tiab] OR metrolyl [tiab] OR quinolone* [tiab] OR ciprofloxacin [tiab] OR ciproxin)

\#15 \#11 OR \#12 OR \#13 OR

$\# 14$

\#16 \#8 AND \#15

\#17 \#10 OR \#16

\begin{tabular}{l|l}
\hline CINAHL (EBSCO) & Web of Science
\end{tabular}

S1 (MH "Pharyngitis")

S2 (MH "Tonsillitis")

S3 TI pharyngit* OR nasopharyngit* OR (retropharyngeal AND abscess) OR (peritonsillar AND abscess) OR tonsillit* OR (sore AND throat) OR (inflamm* AND throat) OR (infect* AND throat) OR pharyngotonsillitis

S4 S1 or S2 or S3

S5 (MH "Recurrence")

S6 (MH "Chronic Disease")

S7 TX (recurr* OR recrudesc*

OR relaps* OR reappear* OR

chronic* OR prophyla* OR prevent ${ }^{*}$ )

S8 S5 or S6 or S7

S9 S4 and S8

S10 (MH "anti-bacterial agents") OR (MH "lactams") OR (MH “quinolones") OR (MH “macrolides”)
\#1 TI=((pharyngit* OR nasopharyngit* OR (retropharyngeal AND abscess) OR (peritonsillar AND abscess) OR tonsillit* OR (sore AND throat) OR (inflamm* AND throat) OR (infect* AND throat) OR pharyngotonsillitis) AND (antibiot* OR (anti AND biot*) OR antimicrobial* OR (anti AND microbial*) OR bacteriocid OR antibacterial* $\mathrm{OR}$ (anti AND bacterial ${ }^{*}$ ) OR penicillin*

OR amoxicillin OR ampicillin

OR (clavulanic AND acid) OR amoxiclav $\mathrm{OR}$ augmentin $\mathrm{OR}$ ticarcillin OR timentin OR flucloxacillin OR fluampicil OR magnapen OR piperacillin OR tazocin OR cephalosporin* OR cefaclor OR distaclor OR cefadroxil OR baxan OR cefalexin

\section{ICTRP}

sore AND throat OR throat AND infection OR pharyngitis OR tonsillitis OR retropharyngeal OR peritonsillar OR nasopharyngitis

\section{Clinicaltrials.gov}

(recurrent OR relapse OR chronic OR prophylaxis OR prophylactic OR prevention OR preventative OR reappear) AND ((throat AND infection) OR pharyngitis OR tonsillitis) AND (antibiotic OR antibiotics OR antimicrobial OR antimicrobials) 
S11 primaxin or meropenem or meronem or tetracycline* or deteclo or demecleocyclin or ledermycin or doxycycline or vibramycin or minocycline or minocine or oxytetracycline or terramycin or macrolide* or erythromycin or erymax or erythrocin or erythroped or azithromycin or zithromax or clarithromycin or klaricid or telithromycin or ketek or trimoxazole or septrin or trimethoprim or monotrim or trimopan or metronidazole or flagyl or metrolyl or quinolone* or ciprofloxacin or ciproxin S12 antibiot* or (anti and biot $^{*}$ ) or antimicrobial* or (anti and microbial $^{*}$ ) or bacteriocid or antibacterial ${ }^{*}$ or (anti and bacterial $^{*}$ ) or penicillin* or amoxicillin or ampicillin or (clavulanic and acid) or amoxiclav or augmentin or ticarcillin or timentin or flucloxacillin or fluampicil or magnapen or piperacillin or tazocin or cephalosporin* or cefaclor or distaclor or cefadroxil or baxan or cefalexin or ceporex or keflex or cefamandole or kefadol or cefazolin or kefzol or cefixime or suprax or cefotaxime OR claforan OR cefoxitin OR mefoxin OR cefpirome OR cefrom OR cefpodoxime OR orelox OR cefprozil OR cefzil OR cefradine OR velosel OR ceftazidime OR fortum OR kefadim OR ceftriaxone OR rocephin OR cefuroxime OR zinacef OR zinnat OR cefonicid OR aztreonam OR azactam OR imipenem OR cilastatin

S13 S10 or S11 or S12

S14 S9 and S13

S15 (MH "antibiotic prophylaxis")
OR ceporex))

\#2 TI=((pharyngit* OR nasopharyngit* OR (retropharyngeal AND abscess) OR (peritonsillar AND abscess) OR tonsillit* OR (sore AND throat) OR (inflamm* AND throat) OR (infect* AND throat) OR pharyngotonsillitis) AND (keflex OR cefamandole OR kefadol OR cefazolin OR kefzol OR cefixime OR suprax OR cefotaxime OR claforan OR cefoxitin OR mefoxin OR cefpirome OR cefrom OR cefpodoxime OR orelox OR cefprozil OR cefzil OR cefradine OR velosel OR ceftazidime OR fortum OR kefadim OR ceftriaxone OR rocephin OR cefuroxime OR zinacef OR zinnat OR cefonicid OR aztreonam OR azactam OR imipenem OR cilastatin))

\#3 $\mathrm{TI}=(($ pharyngit* $\mathrm{OR}$ nasopharyngit* OR (retropharyngeal AND abscess) OR (peritonsillar AND abscess) OR tonsillit* OR (sore AND throat) OR (inflamm* AND throat) OR (infect* AND throat) OR pharyngotonsillitis) AND (primaxin OR meropenem or meronem or tetracycline* or deteclo or demecleocyclin or ledermycin or doxycycline or vibramycin or minocycline or minocine or oxytetracycline or terramycin OR macrolide* OR erythromycin OR erymax OR erythrocin OR erythroped OR azithromycin OR zithromax OR clarithromycin OR klaricid OR telithromycin OR ketek OR trimoxazole OR septrin OR trimethoprim OR monotrim OR trimopan OR metronidazole OR flagyl OR

Antibiotics for preventing recurrent sore throat (Review)

Copyright () 2015 The Cochrane Collaboration. Published by John Wiley \& Sons, Ltd. 
metrolyl OR quinolone* OR ciprofloxacin OR ciproxin)) \#4 \#3 OR \#2 OR \#1

\#5 TS=(recurr* OR recrudesc* OR relaps* OR reappear* OR chronic* OR prophyla* OR prevent $^{*}$ )

\#6 \#4 AND \#5

\section{CONTRIBUTIONSOFAUTHORS}

Gareth Ng, Stephanie Tan and Anh Vu wrote the protocol under the guidance and supervision of Chris Del Mar and Mieke van Driel. Gareth Ng and Stephanie Tan wrote the review under the guidance and supervision of Chris Del Mar and Mieke van Driel.

\section{DECLARATIONSOF INTEREST}

There are no real or perceived biases in regards to this review introduced by the receipt of any benefit in cash or in kind, any hospitality or any subsidy derived from any source that may have or be perceived to have an interest in the outcome of the review.

Gareth JY Ng: none known.

Stephanie Tan: none known.

Anh N Vu: none known.

Chris B Del Mar: none known.

Mieke L van Driel: none known.

\section{SOURCES OF SUPPORT}

\section{Internal sources}

- No sources of support supplied

\section{External sources}

- National Institute for Health Research, UK.

Infrastructure funding for the Cochrane ENT Group 


\section{DIFFERENCES BETWEEN PROTOCOLANDREVIEW}

We have added details of the method that we will use to create a 'Summary of findings' table, if studies are identified for inclusion in future updates of this review.

\section{NDEX TERMS}

\section{Medical Subject Headings (MeSH)}

Anti-Bacterial Agents [*therapeutic use]; Pharyngitis [drug therapy; * prevention \& control]; Recurrence; Secondary Prevention $\left[{ }^{*}\right.$ methods $]$

\section{MeSH check words}

Adult; Child; Humans 